\title{
FIFTH ANNUAL LIST OF PAPERS
}

READ BEFORE THE AMERICAN MATHEMATICAL SOCIETY AND SUBSEQUENTLY PUBLISHED, INCLUDING REFERENCES TO THE PLACES OF THEIR PUBLICATION.

BAKer, A. L. Algebraic Symbols. Read Aug. 28, 1895. American Journal of Mathematics, vol. 18, No. 1, pp. 62-73; Jan., 1896.

Echols, W. H. On the Expansion of a Function without Use of Derivatives. Read Aug. 27, 1895. Annals of Mathematics, vol. 10, No. 1, pp. 17-21 ; Nov., 1895.

- On the Calculus of Functions Derived from Limiting-Ratios. Read May 25 and Aug. 27, 1895. Annals of Mathematics, vol. 10, Nos 2 and 3, pp. 50-76; Jan. and March, 1896.

Hathaway, Arthur S. Elementary Proof of the Quaternion Associative Principle. Read Aug. 28, 1895. Bulletin of the American Mathematical Society, vol. 2, No. 2, pp. 43-45 ; Nov., 1895.

Henderson, R. Moral Values. Read Oct. 26, 1895 . Bulletin of the American Mathematical Society, vol. 2, No 2, pp. 46-51; Nov., 1895.

HILL, G. W. The Periodic Solution as a First Approximation in the Lunar Theory. Read Aug. 27, 1895. Astronomical Journal, No. 352 (vol. 15, No. 17), pp. 137-143; Sept. 7, 1895.

- On the Convergence of the Series used in the Subject of Perturbations. Read Nov. 30, 1895. Bulletin of the American Mathematical Society, vol. 2, No. 4, pp. 93-97 ; Jan., 1896.

- Remarks on the Progress of Celestial Mechanics since the Middle of the Century. [Presidential Address.] Read Dec. 27, 1895 . Bulletin of the American Mathematical Society, vol. 2, No. 5, pp. 125-136 ; Feb., 1896. Science, New Series, vol. 3, No. 62, pp. 333-341; March 6, 1896.

MCMAHON, JAMES. Notes on the Expression for a Velocity-Potential in terms of Functions of Laplace and Bessel. Read Dec. 27, 1895. Bulletin of the American Mathematical Society, vol. 2, No. 6, pp. 173-177; March, 1896.

Martin, Artemas. About Biquadrate Numbers whose Sum is a Biquadrate Number. Read May 25, 1895. Mathematical Magazine, vol. 2, No. 10, pp. 173-184; Jan., 1896.

- About Cube Numbers whose Sum is a Cube Number (Second Part.) Read Aug. 15, 1895. Mathematical Magazine, vol. 2, No. 10, pp. 185-190; Jan., 1896.

Maschke, H. Asymptotic Lines on a Circular Ring. Read Aug. 28, 1895. Bulletin of the American Mathematical Society, vol. 2, No. 1, pp. 19-21; Oct., 1895.

Moore, Eliakim Hastings. Concerning Jordan's Linear Groups. Read Aug. 28, 1895. Bulletin of the American Mathematical Society, vol. 2 , No. 2, pp. 33-43; Nov., 1895. 
A Two-Fold Generalization of Fermat's Theorem. Read Feb. 29, 1896. Bulletin of the American Mathematical Society, vol 2, No. 7, pp. 189-199 ; April, 1896.

MoRLEY, F. On a Generalization of Weierstrass's Equation with Three Terms. Read Aug. 27, 1895 . Bulletin of the American Mathematical Society, vol. 2, No. 1, pp. 21-22 ; Oct., 1895.

- Note on the Common Tangents of Two Similar Cycloidal Curves. Read Nov. 30, 1895. Bulletin of the American Mathematical Society, vol. 2, No. 4, pp. 111-116 ; Jan., 1896.

Newson, H. B. On a Remarkable Covariant of a System of Quantics. Read March 28, 1896. Bulletin of the American Mathematical Society, vol. 2, No. 8, pp. 272-275; May, 1896.

Roberts, RALPH A. On the Differential Equations of Certain Systems of Conics. Read Aug. 28, 1895 . Bulletin of the American Mathematical Society, vol. 2, No. 1, pp. 11-19; Oct., 1895.

- On the Locus of the Foci of Conics having Double Contact with Two Fixed Conics. Read Nov. 30, 1895 . Bulletin of the American Mathematical Society, vol. 2, No. 4, pp. 98-110 ; Jan. 1896.

TABER, HENRy. On the Automorphic Linear Transformation of an Alternate Bilinear form. Read Jan. 26, $1895 . \quad$ Mathematische Annalen, vol. 46, No. 4, pp. 561-583 ; Nov., 1895.

On Certain Sub-Groups of the General Projective Group. Read Jan. 25, 1896. Bulletin of the American Mathematical Society, vol. 2, No. 7, pp. 221-230; April, 1896.

White, HenRy S. Kronecker's Linear Relation among Minors of a Symmetric Determinant. Read Jan. 25, 1896. Bulletin of the American Mathematical Society, vol. 2, No. 5, pp. 136-138; Feb., 1896. 